\title{
The Impact of Mobile Ordering Service on Offline Store Diversity and Product Diversity
}

\author{
Yujin Hwang \\ KAIST College of Business \\ yj0128@ kaist.ac.kr
}

\author{
Nakyung Kyung \\ KAIST College of Business \\ knkyung@kaist.ac.kr
}

\author{
Dongwon Lee \\ HKUST Business School \\ dongwon@ust.hk
}

\author{
Jaemin Jung \\ KAIST Moon Soul Graduate School of \\ Future Strategy \\ nettong@kaist.ac.kr
}

\author{
Sung-Hyuk Park \\ KAIST College of Business \\ sunghyuk.park@kaist.ac.kr
}

\begin{abstract}
Offline retail stores have adopted mobile ordering technology to enhance their customer experience. A mobile ordering channel allows customers to find a nearby store and choose a product by lowering the search costs. However, the impact of mobile ordering services on the diversity of customer experiences has not been examined. In this study, the effects of mobile ordering technology on store and product diversity are measured. We analyzed the transaction data of 170,635 users over 16 weeks of store visits. The effect of mobile ordering technology on store and product diversity was estimated using the difference-in-differences method. We find that mobile ordering services can positively affect store and product diversity. The results are consistent after analyzing the data resampled with propensity score matching. This study provides the managerial implication that mobile ordering technology is valuable for offline retail stores that aim to extend their customers' shopping and product experiences.
\end{abstract}

\section{Introduction}

Global retail sales are projected to reach US $\$ 26.1$ trillion in 2020 (statista.com), of which US\$21.3 trillion (about $81.6 \%$ of the total) will be from physical stores. Many offline-based retail companies have adopted mobile ordering technology to provide a better shopping experience to their customers, through digital transformation, and others plan to digitize their customer journeys soon. Brakus et al. [7] suggested that customer experiences in offline-based businesses can be separated into product, shopping and service, consumption, and brand experiences. We focus on the impact of digital technology on the shopping and service experiences of customers in a physical store and their product experiences.

We expect three features of mobile ordering services-low search cost, accessibility, and remote ordering - will make customer experiences more diverse. Digital technology in the online economy has been found to lower search costs, which positively affects product variety $[8,17,26]$. Personalized digital services provide location-based store information, including a list of nearby stores with service hours and available menus, so such technology will naturally help extend store diversity for customers. The universal and ubiquitous connectivity $[13,14]$ of the mobile app can also contribute to diversifying customers' purchases by increasing their brand engagement [21]. Mobile connectivity can also encourage customers' impulse buying $[21,29]$ or variety-seeking behavior in response to real-time targeted advertising, which may increase product and store diversity. Mobile ordering services have the significant advantage of reducing waiting time in stores, through the use of remote ordering functions [12]. The convenience this provides can help avoid negative experiences in unfamiliar stores, positively affect customer loyalty, and increase store and product diversity.

However, to the best of our knowledge, the impact of such digital technology on the diversity of customer experiences in offline-based retail stores has not been thoroughly investigated. Thus, our main research questions are the following: (1) Does the use of mobile ordering applications increase the level of physical store diversity? (2) Does the use of mobile ordering applications increase the level of product diversity?

For our empirical analysis, we used individual-level purchase data over 16 weeks, collected by a Korean 
leading retail and foodservice company, with 8 weeks before and 8 weeks after the launch of a new mobile ordering application. Of the 170,635 users, those who had used the mobile ordering app were defined as the treatment group. Those who had never used the application were defined as the control group. We then defined the period before and after the launch of the app and estimated the effect of the mobile ordering experience on the store and product diversity using the difference-in-differences method. To control for any systematic difference between users who used the mobile ordering service and those who did not, the analysis was repeated after conducting propensity score matching (PSM). The results provide empirical evidence that using a mobile ordering application increases the levels of store diversity and product diversity.

This is the first empirical study to demonstrate the positive impact of a mobile ordering service on both store and product diversity. Our findings help to identify the relationship between the adoption of such digital technology and the level of customer experience.

\section{Related literature}

\subsection{Mobile ordering and diverse customer experience}

Mobile ordering is distinct from offline ordering in physical stores via face-to-face interactions, in terms of (1) low search cost, (2) increased accessibility, and (3) remote ordering. In this section, we investigate how these features contribute to customers' purchasing diversity, i.e., store diversity and product diversity.

2.1.1. Low search cost Mobile ordering services generally offer store and product information, which customers typically need when making offline purchases. Mobile ordering apps often contain decision aid tools such as a keyword search, recommendation system, and shopping cart [18, 22]. With the help of these functions, customers can efficiently search, view, store, compare and re-evaluate multiple stores and products.

\section{Store diversity}

Location-based store recommendations are essential decision aid tools in mobile ordering apps. A locationbased service lowers search costs and helps customers easily find the nearest store, even in an unfamiliar area [14]. Thus, the likelihood of customers finding new stores that they had not previously visited increases.

In addition to location-based lists of nearby stores, the app provides information so customers can find stores based on their current needs (e.g., real-time inventory statuses) or situational context (e.g., opening hours, parking availability, drive-thru availability). If they find a new store that suits their needs, they are more likely to visit it instead of the stores they frequently visit.

\section{Product diversity}

The low search cost allows customers to access a wider variety of products with less time and effort. Thus, they can discover niche products, increasing the size of their consideration set. The role of low search cost on product diversity has been investigated in many studies of recommendation systems. For example, Brynjolfsson et al. [8] found that in a condition where product availability and price are the same, reduced search costs allow customers to obtain information about various products, thereby expanding their consideration set and increasing the likelihood of buying niche products. Lee and Hosanagar [26] also showed that cross-category consumption at an individual level increases with a recommendation system. Thus, evidence suggests that a mobile ordering app will reduce the search costs when compared to offline ordering and will encourage customers to consume various products.

2.1.2. Increasing accessibility Mobile devices are portable and have universal connectivity, so customers can access the Internet and search for information regardless of time or location $[13,14]$. This connectivity enables customers to search and take action (e.g., place an order) immediately $[25,30]$. Location-based targeted advertising sent by marketers can also be checked in real-time.

\section{Store diversity}

A mobile device allows a company to keep track of customer information, including their locations [13, 14, $15,16,17]$. A mobile ordering app can then push the promotion or discount offers of nearby stores [16]. Thus, the universal and ubiquitous connectivity of mobile devices that enables instant search and purchase can induce customers' impulse purchases [21, 29]. In response to targeted advertising, customers are likely to visit stores they have not previously visited to enjoy discounts or promotional offers.

\section{Product diversity}

Ubiquitous Internet access enables customers to obtain product information at any time, even if they are not in a purchasing situation. Jung et al. [21] showed that mobile app adopters access and engage with apps more often and longer than non-adopters. Lee et al. [25] found that customers who use mobile device purchase more diverse products than PC-based customers do. Thus, mobile ordering app adoption will increase brand 
engagement and make customers more aware of product information, resulting in more diverse product purchases.

Marketers can also induce diverse product consumption through targeted advertising. They can stimulate the desire for variety in customers by sending information about the new products or specialized menus. A mobile app can acquire useful information about customers' preferences, so advertising can be made more effective in diversifying customers' purchases when marketers incorporate purchase history, time, and the spatial and social context into location information $[13,15,16,17]$.

2.1.3. Remote ordering Offline services, such as those of restaurants, involve an ordering stage and a product preparation stage, which leads to customer waiting time in a store [12]. However, mobile ordering services allow customers to pre-order items and collect them at a designated store location [11], thus reducing waiting time in a store [12].

\section{Store diversity}

The remote ordering function of mobile ordering services not only enables customers to avoid interaction with a cashier [12] but also reduces the likelihood of facing a crowded or unfamiliar environment. Their perceptions about a store and their emotions and behavior can be negatively affected by encountering crowds or eye contact with strangers $[2,20]$. As it helps customers avoid such unpleasant experiences, a mobile ordering service may reduce their reluctance to visit new stores and increase the possibility of visiting diverse stores.

\section{Product diversity}

Customers can spend sufficient time searching for products, without caring about other customers standing in line, before they place a mobile order. This allows them to explore a variety of products, and the probability of purchasing more diverse products increases. Remote ordering also reduces waiting time, and previously unproductive time becomes productive [13], and can benefit customers who are more sensitive to waiting [12]. Providing such convenience can positively affect service quality and satisfaction, and ultimately service loyalty [5, 9, 24]. As loyalty or involvement increases, customers actively search for and process product information about the brand [34], and thus are more likely to pursue variety within a brand. The probability of customers buying a variety of products then increases.

\subsection{The impact of diverse customer experiences}

Customer behavior has generally been viewed as an experiential dimension, and much of the marketing literature has focused on holistic customer experiences and the interactions between customers and a brand [6, $7,19,33]$. Purchasing various products or visiting multiple stores can thus be viewed as the process of enriching and broadening the customer experience, creating "sensory, emotional, cognitive, behavioral, and relational values" [33].

Expanding the experiences of customers satisfies their desire for variety and increases the probability of retaining them by preventing further variety-seeking behavior. The repeated choice of a product or a store has been found to induce a perception of boredom or a lack of stimulation [3,10,27,28], becoming neither novel nor providing freshness (i.e., new stimuli) to the customer [4]. Thus, alternative store and product choices provide a stimulus of different brand-related attributes to the individual [27] and offer customers "fantasies, feelings, and fun" [19]. The natural curiosity of customers may lead them to switch products or services [32], so providing a variety of experiences prevents reaching the satiation level and prevents churn [27, 28]. Park and Han [31] empirically identified that the greater the variety of products customers consume, the higher their retention rate.

Various experiences, including diverse store experiences, can positively affect brand personality, brand satisfaction, and loyalty [6, 7]. A store's atmosphere can be viewed as "a message-creating medium" for customers [23]. Experiencing various store atmospheres can affect how brand personalities are unconsciously perceived. Interactions with various brand-related staff (e.g., salespeople) also lead customers to infer a particular brand personality $[1,7]$. Brand personality differentiates a brand and affects customer loyalty [7]. Experience can also increase customer satisfaction because it provides value and utility [7].

From the perspective of a brand, expanding the customer experience regarding products and stores increases its brand competitiveness [33]. For example, McDonald's main products are burgers, but the company has become a competitor to Starbucks because its take-out snacks and coffee account for an increasing proportion of its sales. Likewise, selling a variety of products opens up new market opportunities that enable brand expansion. If a brand diversifies in its product and store sales, it is more likely to survive in the wider market, even it fails in a specific category or region. 


\section{Data}

Transaction data obtained from a leading retail and foodservice company in Korea were used in this study. The brand adopted a mobile ordering system on May 7, 2019. We leveraged this event as a shock (i.e., treatment) and applied a natural experiment setting. Thus, we examined the effect of an exogenous treatment (i.e., the mobile ordering adoption event) on customer behavior using the difference-in-differences approach. We obtained panel data over 16 weeks: 8 weeks before and 8 weeks after the launch of the new mobile ordering application. The panel set contains the purchase history of 170,635 unique users. We also obtained data on age, gender, membership period, and membership level as user characteristics. If they had used the mobile ordering service, we allocated customers to the treatment group, while we allocated users to the control group if they had never used a mobile ordering service.

Our dependent variables are store diversity and product diversity. Store diversity refers to the number of distinct stores visited by a customer during the period. Product diversity refers to the number of product categories purchased by a customer, out of the five categories of Coffee, Noncoffee drinks, Dessert, Bakery, and Meal. We calculate each user's store and product diversity for both pre- and post-mobile ordering adoption.

To alleviate concerns about systematic differences between the control and treatment groups, we used recency, frequency, and monetary (RFM) values, membership period, and membership level for PSM. We measured Recency by the most recent purchase dates in the prior period, calculated as the difference between the date of the customer's last visit in the prior period and the mobile ordering app launch day. Thus, the lower the number, the more recent the purchase. Frequency indicates a customer's purchase frequency (i.e., number of bills), and Monetary is the total amount that a customer spent during the period. Membership period refers to the date since the membership registration on the app or website. Membership level increases through silver, gold, and red levels, and each level is translated into a dummy variable and used in the analysis.

\section{Analysis and Results}

To examine the effect of the mobile ordering service on store and product diversity, we applied a differencein-differences approach. In this difference-indifferences estimation, we examined the treatment group before and after treatment and used a control group. The empirical model for the difference-indifferences estimation is as follows:

$$
\begin{aligned}
\text { Outcome }_{i t} & =\beta_{0}+\beta_{1} \text { Treat }_{i}+\beta_{2} \text { After }_{t} \\
& +\beta_{3} \text { Treat }_{i} \times \text { After }_{t}+\theta_{i}+\delta_{t}+\varepsilon_{i t}
\end{aligned}
$$

Outcome $_{i t}$ refers to Store diversity or Product diversity. Treat $_{i}$ indicates whether user $i$ has used a mobile ordering service in the post-period and After $r_{t}$ denotes whether time $t$ is post-period or not. $\theta_{i}$ and $\delta_{i}$ represent time-invariant individual-specific fixed effects and time fixed effects, respectively, and $\varepsilon_{i t}$ is the error term. $\beta_{3}$ captures the impact of the mobile ordering service on the change in the purchase patterns of both the treatment and control group customers.

Tables 1 and 2 report the results of the difference-indifferences estimation of changes in store diversity and product diversity after adopting the mobile ordering service. Table 1 implies that the service has a significant and positive influence on store diversity. The number of stores visited by a customer during the post-period is, on average, 0.176 higher for mobile ordering users than non-users, even after estimating fixed effects. Table 2 shows that the mobile ordering service has a positive impact on product diversity. The users of the mobile ordering app have 0.204 more product category diversity than non-users. Thus, we can conclude that using a mobile ordering system leads to diverse customer experiences, increasing store and product diversity.

\section{Table 1. Estimation results}

\begin{tabular}{|c|c|c|c|c|}
\hline \multirow{5}{*}{$\begin{array}{l}\text { Treat } \\
\text { After } \\
\text { Treat * After } \\
\text { Constant }\end{array}$} & \multicolumn{4}{|c|}{ Store Diversity } \\
\hline & $-0.021^{* \star *}$ & $(0.003)$ & $-0.021^{\star \star *}$ & $(0.002)$ \\
\hline & $0.247^{* * *}$ & $(0.013)$ & Omitted & \\
\hline & $0.176^{* * *}$ & $(0.019)$ & $0.176^{\star \star *}$ & $(0.014)$ \\
\hline & $1.532^{\star \star \star}$ & $(0.002)$ & $1.539^{\star * *}$ & $(0.002)$ \\
\hline Observations & \multicolumn{2}{|c|}{341,270} & \multicolumn{2}{|c|}{341,270} \\
\hline $\begin{array}{l}\text { Individual } \\
\text { Fixed effects }\end{array}$ & \multicolumn{2}{|c|}{ No } & \multicolumn{2}{|c|}{ Yes } \\
\hline R-squared & \multicolumn{2}{|c|}{0.0041} & \multicolumn{2}{|c|}{0.7171} \\
\hline Adj. R-squared & \multicolumn{2}{|c|}{0.0041} & \multicolumn{2}{|c|}{0.4343} \\
\hline Root MSE & \multicolumn{2}{|c|}{0.8983} & \multicolumn{2}{|c|}{0.6770} \\
\hline
\end{tabular}
for store diversity

Table 2. Estimation results

\begin{tabular}{|c|c|c|c|c|}
\hline \multirow[b]{2}{*}{ Treat } & \multicolumn{4}{|c|}{ Store Diversity } \\
\hline & $-0.026^{\star \star \star}$ & $(0.003)$ & $-0.026^{\star \star \star}$ & $(0.003)$ \\
\hline After & $0.266^{\star \star *}$ & $(0.014)$ & Omitted & \\
\hline Treat * After & $0.204^{* * *}$ & $(0.020)$ & $0.204^{* * *}$ & (0.016) \\
\hline Constant & $1.936^{\star * *}$ & $(0.002)$ & $1.943^{* * *}$ & $(0.002)$ \\
\hline Observations & \multicolumn{2}{|c|}{341,270} & \multicolumn{2}{|c|}{341,270} \\
\hline $\begin{array}{l}\text { Individual } \\
\text { Fixed effect }\end{array}$ & \multicolumn{2}{|c|}{ No } & \multicolumn{2}{|c|}{ Yes } \\
\hline R-squared & \multicolumn{2}{|c|}{0.0044} & \multicolumn{2}{|c|}{0.6832} \\
\hline Adj. R-squared & \multicolumn{2}{|c|}{0.0044} & \multicolumn{2}{|c|}{0.3665} \\
\hline Root MSE & \multicolumn{2}{|c|}{0.9524} & \multicolumn{2}{|c|}{0.7597} \\
\hline
\end{tabular}
for product diversity

Although we estimated individual fixed effects, any systematic difference between users who used the mobile ordering service and those who did not should 
also be controlled for. Gao and $\mathrm{Su}$ [12] found that customers using mobile ordering apps are those who are sufficiently involved with the brands to download their apps. This may lead to different product and store consumption behaviors. To resolve this issue, we used PSM to identify among all users who did not use mobile ordering, those with similar observed characteristics to those who used mobile ordering. We used customers' demographic profile (age and gender), service tenure (membership period and membership level), and RFM values in the prior period to estimate a user's propensity score. After matching, 9,467 samples were retained from the 170,635 users. Note that all of the variables used for PSM are not significantly different for the mobile ordering users and the non-users, implying that PSM ensures a statistical balance between them. The difference-in-differences estimates using the matched samples are consistent with our main findings.

\section{Conclusion}

The mobile revolution has fundamentally reshaped how customers reach and engage with stores and products, and mobile ordering services, characterized by real-time ordering through a mobile application, are widely used to improve shopping experiences. Despite the ongoing increase in the popularity of mobile ordering, the impact of its use on customers' shopping and product experiences, i.e., product and store diversity, has not been examined. Thus, our objective is to empirically investigate the effect of mobile ordering on product and store diversity. By leveraging large-scale user-level purchase data from a major retail company in South Korea and using difference-in-differences estimation, we find that the use of a mobile ordering service increases both product and store diversity, implying that the adoption of mobile ordering technology leads to diverse customer experiences. These results should be of interest to businesses aiming to improve their customers' shopping experiences.

This study makes the following contributions. First, it contributes to the literature addressing the impact of mobile technology-based marketing on customer experience. The impact of mobile technology on sales dispersion and the effectiveness of targeted advertising has been investigated [15, 17], but little attention has been paid to how mobile technology affects the diversity of customer experiences compared with offline purchasing. In particular, the effect of mobile technology on store diversity has not been examined. Data on individual purchase behavior are used in this study to identify positive customer experiences after using a mobile ordering service. The improved customer shopping and product experiences after using the service suggest that mobile ordering can satisfy the desire for variety by decreasing search costs, and can increase customer loyalty by providing more convenience.

We also provide practical implications for retailers and marketers. The positive effect of mobile ordering services on both product and store diversity suggests that marketing resources should be allocated not only to mobile coupons or web-based orders but also to the development of mobile ordering systems. Several studies have shown that extending customers' brand experiences can positively affect their brand satisfaction, loyalty, and the probability of retaining them [7, 27, 28, 31]. Expanding customer experience also makes brands more competitive and can reveal new market opportunities [33]. Thus, a mobile ordering service can represent a direct strategy to differentiate a brand by enabling various customer experiences and satisfying their desire for variety.

This study has several limitations, which we believe can provide opportunities for future research. First, in our empirical analysis, we attempted to control for time and individual fixed effects using the difference-indifferences method and accounted for potential differences between mobile users and non-users by applying the PSM method. However, omitted variable bias may be a problem. Thus, we plan to extend our model by including additional variables such as user characteristics or brand promotion activities. Second, we defined two periods based on the mobile ordering app launch date. However, consumers are likely to adopt a mobile app at different times. Thus, as a next step, we will apply a dynamic matching method and use a relative time frame. Third, we explored the influence of a mobile ordering service on purchase diversity at the individual level. This influence can also be assessed at the aggregate level. Finally, other variables may amplify the effect of mobile ordering on customers' purchase diversity. For example, the effects of time (AM vs. PM), day (weekday vs. weekend), and user characteristics (membership level or relative purchase diversity before adopting a mobile ordering service) can be examined.

Despite the above limitations, this is the first study to examine the impact of a mobile ordering service on store and product diversity by leveraging purchase data. Our findings can serve as a basis for further studies into mobile ordering services, and help researchers, businesses, and marketers expand their customers' shopping experiences and increase their loyalty.

\section{References}

[1] Aaker, J. L., "Dimensions of brand personality", Journal of Marketing Research, 34(3), 1997, pp.347-356.

[2] Albas, D. C. and C. A. Albas, "Meaning in context: The impact of eye contact and perception of threat on 
proximity", Journal of Social Psychology, 129(4), 1989, pp.525-531.

[3] Bawa, K., "Modeling inertia and variety seeking tendencies in brand choice behavior", Marketing Science, 9(3), 1990, pp.263-278.

[4] Berlyne, D. E., "Conflict, arousal, and curiosity", 1960.

[5] Bielen, F. and N. Demoulin, "Waiting time influence on the satisfaction-loyalty relationship in services", Managing Service Quality: An International Journal, 2007.

[6] Brakus, J. J., B. H. Schmitt, and S. Zhang, "13. Experiential attributes and consumer judgments", Bresciani, Valdés y Elgar, Handbook on Brand and Experience Management: The Role of Agriculture in Poverty Reduction, 2007, pp.174.

[7] Brakus, J. J., B. H. Schmitt, and L. Zarantonello, "Brand experience: what is it? How is it measured? Does it affect loyalty?". Journal of Marketing, 73(3), 2009, pp.52-68.

[8] Brynjolfsson, E., Y. Hu, and D. Simester, "Goodbye pareto principle, hello long tail: The effect of search costs on the concentration of product sales", Management Science, 57(8), 2011, pp.1373-1386.

[9] Caruana, A., "Service loyalty", European journal of marketing, 2002.

[10] Coombs, C. H., and G. S. Avrunin, "Single-peaked functions and the theory of preference", Psychological Review, 84(2), 1977, pp.216.

[11] Elston, S., B. Smith, D. Edelstein, C. Wenkoff, K. Brown, B. Lonac, and J. Strashek, "Remote ordering system for mobile commerce.", U.S. Patent Application No. 10/082, 057, 2002.

[12] Gao, F., and X. Su, "Omnichannel service operations with online and offline self-order technologies", Management Science, 64(8), 2018, pp.3595-3608.

[13] Ghose, A., "TAP: Unlocking the mobile economy", MIT Press, 2017.

[14] Ghose, A., A. Goldfarb, and S. P. Han, "How is the mobile Internet different? Search costs and local activities", Information Systems Research, 24(3), 2013, pp.613-631.

[15] Ghose, A., B. Li, and S. Liu, "Mobile targeting using customer trajectory patterns", Management Science, 65(11), 2019, pp.5027-5049.

[16] Ghose, A., B. Li, and S. Liu, "Nudging mobile customers with real-time social dynamics", SSRN 3587715, 2020.

[17] Goldfarb, A., and C. Tucker, "Digital economics", Journal of Economic Literature, 57(1), 2019, pp.3-43.

[18] Häubl, G., and V. Trifts, "Consumer decision making in online shopping environments: The effects of interactive decision aids", Marketing Science, 19(1), 2000, pp.4-21.

[19] Holbrook, M. B., and E. C. Hirschman, "The experiential aspects of consumption: Consumer fantasies, feelings, and fun", Journal of Consumer Research, 9(2), 1982, pp.132-140.
[20] Hui, M. K., and J. E. Bateson, "Perceived control and the effects of crowding and consumer choice on the service experience", Journal of Consumer Research, 18(2), 1991, pp.174-184.

[21] Jung, J., R. Bapna, J. Ramaprasad, and A. Umyarov, "Love unshackled: Identifying the effect of mobile app adoption in online dating", MIS Quarterly, 43, 2019, pp.47-72.

[22] Kaufman-Scarborough, C., and J. D. Lindquist, "Eshopping in a multiple channel environment", Journal of Consumer Marketing, 19(4), 2002, pp.333-350.

[23] Kotler, P. "Atmospherics as a marketing tool". Journal of Retailing, 49(4), 1973, pp.48-64.

[24] Ladhari, R., I. Brun, and M. Morales, "Determinants of dining satisfaction and post-dining behavioral intentions", International Journal of Hospitality Management, 27(4), 2008, pp.563-573.

[25] Lee, D., A. Gopal, and S. H. Park, "Different but Equal? A Field Experiment on the Impact of Recommendation Systems on Mobile and Personal Computer Channels in Retail", Information Systems Research, 31(3), 2020, pp.892-912.

[26] Lee, D., and K. Hosanagar, "How do recommender systems affect sales diversity? A cross-category investigation via randomized field experiment", Information Systems Research, 30(1), 2019, pp.239-259.

[27] McAlister, L. "A dynamic attribute satiation model of variety-seeking behavior", Journal of Consumer Research, 9(2), 1982, pp.141-150.

[28] McAlister, L., and E. Pessemier, "Variety seeking behavior: An interdisciplinary review", Journal of Consumer Research, 9(3), 1982, pp.311-322.

[29] Narang, U., and V. Shankar, "Mobile app introduction and online and offline purchases and product returns", Marketing Science, 38(5), 2019, pp.756-772.

[30] Okazaki, S., amd F. Mendez, "Perceived ubiquity in mobile services", Journal of Interactive marketing, 27(2), 2013, pp.98-111.

[31] Park, S. H., and S. P. Han, "From accuracy to diversity in product recommendations: Relationship between diversity and customer retention", International Journal of Electronic Commerce, 18(2), 2013, pp.51-72.

[32] Raju, P. S. "Optimum stimulation level: Its relationship to personality, demographics, and exploratory behavior", Journal of Consumer Research, 7(3), 1980, pp.272-282.

[33] Schmitt, B., "Experiential marketing", Journal of Marketing Management, 15(1-3), 1999, pp.53-67.

[34] Warrington, P., and S. Shim, "An empirical investigation of the relationship between product involvement and brand commitment", Psychology \& Marketing, 17(9), 2000, pp.761-782. 